\title{
MULTI-OBJECTIVE OPTIMIZATION OF PLASMA ARC CUTTING PROCESS USING MOORA COMBINED WITH GA
}

\author{
A. Hamdy, M. Fattouh, S. Abaas and R. Masoud \\ Faculty of Engineering, Menoufia University, Shebin Elkom, Egypt
}

\begin{abstract}
:
In this work, cutting parameters were optimized in plasma arc cutting process of mild steel by application of multi-objective optimization by ratio analysis (MOORA) method. Standard deviation (SDV) concept has been used to allocate the weight criteria of each objective being reflected. Cutting speed, arc current, and standoff distance were nominated as setting parameters for optimization the kerf characteristics in the straight-slit cutting (kerf taper, dross, surface roughness and maximization of material removal rate). MOORA was used to transform multiple responses into a single characteristic index known as multi performance characteristic index (MPCI). MPCI was modeled by the use of genetic algorithm (GA). With this action an attempt was made to find more precise dependence of MPCI with cutting parameters. Finally, this was followed by optimization of the MPCI in plasma arc cutting using genetic algorithm. This has also been that, SDV-MOORA-GA method has effectively optimized the plasma arc cutting process parameters used in this study.
\end{abstract}

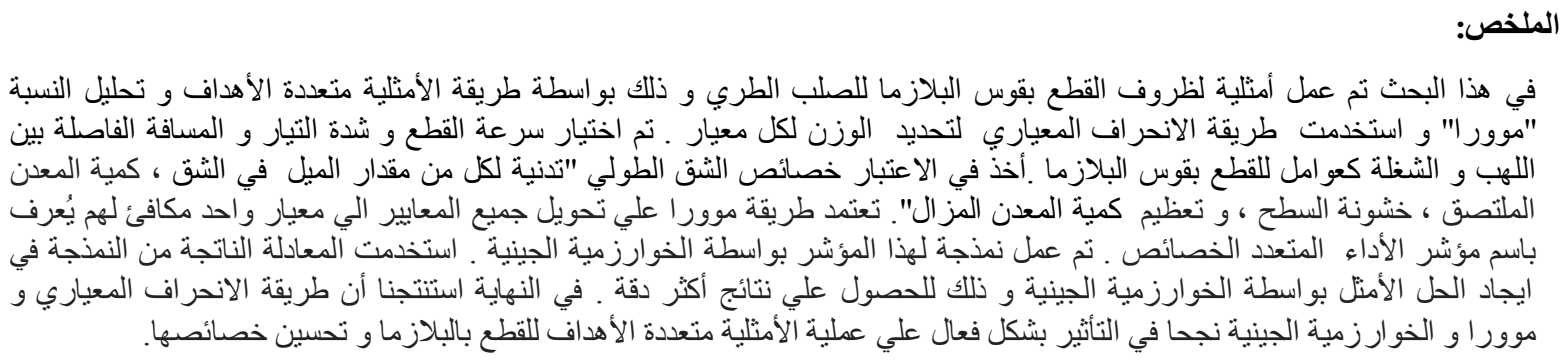

Keywords: Plasma Arc Cutting (PAC) - Multi-Objective Optimization by Ratio Analysis (MOORA) Standard Deviation (SDV) concept -. Genetic Algorithm (GA).

\section{INTRODUCTION}

Plasma Arc Cutting (PAC) is a non-conventional process which can perform numerous electrically conducting materials. Plasma arc cutting can be used for the cutting of metal plates with thickness varying from 4 to $40 \mathrm{~mm}$. The basic principle is that the arc formed between the electrode and the work piece is constricted by a fine bore, copper nozzle. This increases the temperature and velocity of the plasma emanating from the nozzle. The temperature of the plasma is in excess of $20,000{ }^{\circ} \mathrm{C}$. When used for cutting, the plasma gas flow is increased so that the deeply penetrating plasma jet cuts through the material and molten material is removed in the efflux plasma. PAC involves a large number of process parameters. It requires optimization of the process parameters to get smooth operation. The multi-

parameter optimization of the PAC process according to quality indicators, such as the kerf characteristics and the quality of the cut surface has been experimentally studied by several researchers for several materials and experimental conditions [1- 25].
According to the articles which have been reviewed in this work, various materials and process parameters of PAC were studied to find the best cutting characteristics. The Design of Experiments (DoE) techniques such as, Plackett-Burman plans [1], analysis of variance (ANOVA) [ 4], Taguchi [ 4, 8 and 10] and response surface methodology (RSM) [ 26] showed their importance to evaluate the impact of process parameters of PAC. Some researchers investigated the single response optimization problem [1, 4, 8 and 10]. Few researchers have worked on the mathematical modeling of the PAC process and the multi response optimization problem [24] Some of them combined more than one optimization technique to produce optimized cutting. From the literature it was also observed that some multicriteria decision making (MCDM) methods were applied to optimize the PAC process such as, desirability function approach, fuzzy model [14], and grey relational analysis (GRA) [9].

For solving manufacturing environment selection problems MCDM methods have been applied such as, VIKOR method [26], technique for order preference by similarity to ideal solution (TOPSIS) [27 and 28] and 
multi-objective optimization on the basis of ratio analysis (MOORA) [29-34] method, were applied. In real time manufacturing, the decision-making process is more difficult due to various interests and values of different decision makers. There is a need for simple, systematic and logical procedure to solve decisionmaking problems effectively. MOORA method is one of the MCDM methods which use statistical procedure for the selection of the best alternative from the given alternatives. This method was simple and contains lesser mathematical steps. This method was used to convert multi-criteria optimization problems into an equivalent single criteria optimization problem and involves appropriate procedure to solve multiple objectives simultaneously.

Gadakh et al. [29] optimized welding process parameters all together using MOORA method. Chaturvedi et al. [30] investigated electro-chemical machining process for the selection of optimum machining parameters by MOORA method. Gadakh [31] used MOORA method to optimize different milling process parameters simultaneously. Rajesh et al. [32] used Taguchi method combined with MOORA in wear study of composite material for optimization of process parameters simultaneously. Ray [33] optimized suitable cutting fluid in a traditional manufacturing system using MOORA method.

Hence, an effort has been made in the present investigation to combine MOORA, SDV concept and GA for optimization all together a number of response parameters (kerf characteristics in the straight-slit cutting) with respect to the number of setting parameters in PAC of mild steel. MOORA was used to transform multiple responses into a single characteristic index known as Multi Performance Characteristic Index (MPCI). MPCI was modeled by the use of genetic algorithm (GA). With this achievement an effort was made to find more precise dependence of MPCI with cutting parameters. Finally, this was followed by optimization of the MPCI in plasma arc cutting using genetic algorithm. The quality of cut ( $\mathrm{Ra}$, Dross and $\mathrm{K}$. Taper) and material removal rate were considered as the major responses. The cutting speed, current, and standoff distance are acquired as the process parameters.

\section{EXPERIMENTAL RESULTS}

The whole experiment of plasma arc cutting process was carried out on a CNC plasma cutting system, Plasma arc Cutting machine used in this work is hyper therm power max 65 (model SF-2012GC). with the use of air as a plasma (primary) gas and as a shielding (secondary)gas. The parameters of supply voltage, rated power and operating pressure are fixed at $480 \mathrm{~V}, 24.5 \mathrm{~kW}$ and 4.8 bar, respectively. A plate of mild steel having dimensions of $1000 \mathrm{~mm} \times 1000 \mathrm{~mm} \times 4 \mathrm{~mm}$ was prepared for the experimental work. The plate was cut in 27 pieces $(70 \mathrm{~mm} \times 70 \mathrm{~mm} \times 4 \mathrm{~mm})$ as showing in Fig (1) with all combinations of process parameters. The kerf characteristics in the straight-slit cutting on the part was only considered in this paper as one of the areas for measuring the surface roughness, dross and calculating the kerf taper and material removal rate. Cutting speed, arc current and standoff distance are taken as the setting process parameters. The values of setting process parameters are given in Table (1). The quality of cut was considered as the major responses. Surface roughness was measured using surface roughness tester (TR 210). Zoom stereo microscope was used to measure the kerf width in top and bottom sides. Material removal rate was calculated using the following Equation-

\section{MRR =0.5 $(\mathbf{W t}+\mathbf{W b}) \mathrm{T}$ V}

Where $\mathrm{Wt}$ is kerf width at top side, $\mathrm{Wb}$ is kerf width at bottom sided, $\mathrm{T}$ is thickness of specimen, $\mathrm{V}$ is cutting speed required to perform operation and unit for MRR is $\mathrm{mm}^{3} \backslash \mathrm{min}$.

The value of Kerf taper magnitude was calculated using the following Equation

$$
\mathrm{KTM}=(\mathbf{W t}-\mathbf{W b}) / 2
$$

The value of dross was measured by Digital weight balancer equipment APOLLO| GF-A.

The experiments were conducted based on full factorial design method. The complete L27 orthogonal array and experimental results were tabulated in Table (2) and Table (3) respectively.

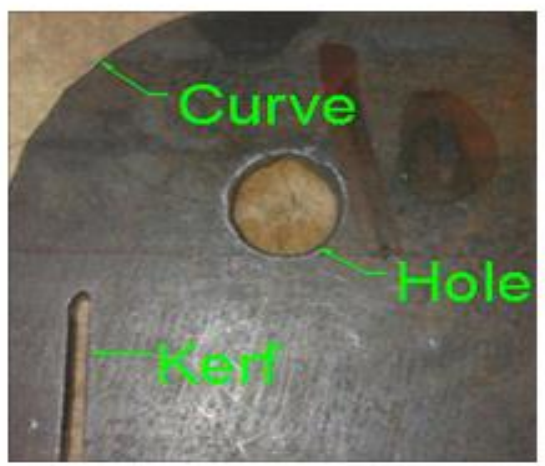

Fig (1) Work piece 
A. Hamdy, M. Fattouh, S. Abaas and R. Masoud "MULTI-OBJECTIVE OPTIMIZATION OF ..."

Table (1) Values of setting process parameters

\begin{tabular}{|c|c|c|c|}
\hline Factors & Level 1 & Level 2 & Level 3 \\
\hline Cutting Speed (mm\min), V & 2000 & 3000 & 4000 \\
\hline Arc Current (A),I & 130 & 150 & 170 \\
\hline $\begin{array}{c}\text { Standoff Distance } \\
\text { (mm),SOD }\end{array}$ & 10 & 12 & 14 \\
\hline
\end{tabular}

Table (2) The complete L27 orthogonal array

\begin{tabular}{|c|c|c|c|c|c|c|c|}
\hline Exp. No & $\begin{array}{l}\mathrm{V} \\
\mathrm{mm} \backslash \mathrm{min}\end{array}$ & $\begin{array}{l}\mathbf{I} \\
\mathbf{A}\end{array}$ & $\begin{array}{l}\text { SOD } \\
\text { mm }\end{array}$ & Exp .No & $\begin{array}{l}\mathrm{V} \\
\mathrm{mm} \backslash \mathrm{min}\end{array}$ & $\begin{array}{l}\mathbf{I} \\
\mathbf{A}\end{array}$ & $\begin{array}{l}\text { SOD } \\
\mathbf{m m}\end{array}$ \\
\hline 1 & 2000 & 130 & 10 & 15 & 3000 & 150 & 14 \\
\hline 2 & 2000 & 130 & 12 & 16 & 3000 & 170 & 10 \\
\hline 3 & 2000 & 130 & 14 & 17 & 3000 & 170 & 12 \\
\hline 4 & 2000 & 150 & 10 & 18 & 3000 & 170 & 14 \\
\hline 5 & 2000 & 150 & 12 & 19 & 4000 & 130 & 10 \\
\hline 6 & 2000 & 150 & 14 & 20 & 4000 & 130 & 12 \\
\hline 7 & 2000 & 170 & 10 & 21 & 4000 & 130 & 14 \\
\hline 8 & 2000 & 170 & 12 & 22 & 4000 & 150 & 10 \\
\hline 9 & 2000 & 170 & 14 & 23 & 4000 & 150 & 12 \\
\hline 10 & 3000 & 130 & 10 & 24 & 4000 & 150 & 14 \\
\hline 11 & 3000 & 130 & 12 & 25 & 4000 & 170 & 10 \\
\hline 12 & 3000 & 130 & 14 & 26 & 4000 & 170 & 12 \\
\hline 13 & 3000 & 150 & 10 & 27 & 4000 & 170 & 14 \\
\hline 14 & 3000 & 150 & 12 & & & & \\
\hline
\end{tabular}


Table (3) Experimental results

\begin{tabular}{|c|c|c|c|c|c|c|c|c|c|}
\hline Exp. No & $\begin{array}{l}\mathbf{R a} \\
\mu \mathrm{m}\end{array}$ & $\begin{array}{c}\text { Dross } \\
\text { gmls }\end{array}$ & $\begin{array}{c}\text { KTM } \\
\text { mm }\end{array}$ & $\begin{array}{l}\text { MRR } \\
\mathrm{mm}^{3} / \mathrm{s}\end{array}$ & Exp. No & $\begin{array}{l}\mathbf{R a} \\
\mu \mathrm{m}\end{array}$ & $\begin{array}{c}\text { Dross } \\
\text { gmls }\end{array}$ & $\begin{array}{c}\text { KTM } \\
\text { mm }\end{array}$ & $\begin{array}{l}\text { MRR } \\
\mathrm{mm}^{3} / \mathrm{s}\end{array}$ \\
\hline 1 & 0.804 & 0.56 & 0.515 & 286.067 & 15 & 0.771 & 0.79 & 0.67 & 494.8 \\
\hline 2 & 0.832 & 0.54 & 0.63 & 321.6 & 16 & 0.979 & 0.64 & 0.485 & 473.8 \\
\hline 3 & 0.835 & 0.56 & 0.68 & 337.867 & 17 & 1.067 & 0.62 & 0.52 & 507.3 \\
\hline 4 & 0.726 & 0.57 & 0.475 & 313.6 & 18 & 1.08 & 0.67 & 0.69 & 555.8 \\
\hline 5 & 0.727 & 0.52 & 0.5 & 332.933 & 19 & 0.759 & 0.9 & 0.675 & 519.6 \\
\hline 6 & 0.736 & 0.49 & 0.615 & 361.533 & 20 & 0.746 & 0.87 & 0.73 & 559.333 \\
\hline 7 & 0.933 & 0.41 & 0.43 & 342.4 & 21 & 0.82 & 0.84 & 0.76 & 584.933 \\
\hline 8 & 0.91 & 0.39 & 0.495 & 368.6 & 22 & 0.877 & 0.8 & 0.73 & 589.333 \\
\hline 9 & 0.856 & 0.39 & 0.57 & 384.667 & 23 & 0.839 & 0.83 & 0.68 & 607.067 \\
\hline 10 & 0.8 & 0.77 & 0.65 & 409.1 & 24 & 0.801 & 0.87 & 0.79 & 648.4 \\
\hline 11 & 0.783 & 0.84 & 0.76 & 451.5 & 25 & 1.212 & 0.7 & 0.675 & 633.333 \\
\hline 12 & 0.837 & 0.84 & 0.74 & 470.5 & 26 & 1.2 & 0.74 & 0.59 & 634.933 \\
\hline 13 & 0.835 & 0.82 & 0.67 & 461.8 & 27 & 1.144 & 0.73 & 0.62 & 664.4 \\
\hline 14 & 0.828 & 0.85 & 0.71 & 491.3 & & & & & \\
\hline
\end{tabular}

\section{RESULTS AND DISCUSSION}

The following steps are adopted to estimate the optimal machining parameters in PAC of mild steel using MOORA and SDV method combined with GA using full factorial deign method.

The MOORA method starts with a decision matrix. The decision matrix is used to represent the experimental results with respect to various output parameters. The decision matrix was furnished in Table (3).

\subsection{Determination of Criteria Weights}

The attributes being considered are more important than others in practical situations. To identify the important attribute, it must be multiplied with its relative importance (weight of the attribute). The weight allocation for each of the output parameters can be determined using Entropy method [26], Analytic Hierarchy Process (AHP) [27] and SDV method [34]. In this study, the weight assignee for each of the output parameters was determined using SDV method.

To determine the SDV for each response, the range normalization was done for the decision matrix using Equation (3) to convert different scales and units among various criteria into common measurable units in order to compute their weights. where max Xij, min Xij are the maximum and minimum values of the criterion $(j)$ respectively. The following step is to determine the SDV using Equation (4).

$\operatorname{SDVj}=\sqrt{\frac{1}{m} \sum_{j=1}^{m}\left(X_{i j}-X_{i j}\right)^{2}}$

Where $\mathrm{X}_{\mathrm{ij}}$ is the mean of the values of the jth criterion after normalization and $\mathrm{j}=1,2, \ldots ., \mathrm{n}$. After computing SDV for all criteria, the weights $\mathrm{Wj}$ of all the criteria considered can be determined using Equation (5)

$\mathrm{Wj}=\frac{S D V j}{\sum_{j=1}^{n} S D V j}$

where $\mathrm{j}=1,2, \ldots \ldots, \mathrm{n}$. These three equations prime to the creation of Table (4).

Table (4) Weights assigned to criteria

\begin{tabular}{|c|c|c|}
\hline nse & $\mathbf{S D V j}$ & $\mathbf{W j}$ \\
\hline $\mathbf{R a}$ & 0.747 & $\begin{array}{ll} & 0.24 \\
4 & \end{array}$ \\
\hline Dross & 0.807 & $\begin{array}{ll} & 0.26 \\
4 & \end{array}$ \\
\hline КTM & 0.715 & $\begin{array}{ll} & 0.23 \\
4 & \end{array}$ \\
\hline MRR & 0.788 & $\begin{array}{ll} & 0.25 \\
8 & \end{array}$ \\
\hline
\end{tabular}

$$
X i j=\frac{X_{i j}-\min _{1<j<n} X i j}{\max _{1<j<n} X i j-{ }_{1<j<n} \min _{1 j}}
$$




\subsection{Application of MOORA}

The process for using MOORA aimed at ranking alternatives was described here under;

Step 1: Normalization of decision matrix was performed in this step. This can be obtained by the following formula

$$
\mathrm{Nij}=\frac{\mathrm{Xij}}{\sqrt{\sum_{i=1}^{m} X i j^{2}}}
$$

where $\mathrm{Xij}$ and $\mathrm{Nij}$ are original and normalized score of decision matrix, respectively

where $\mathrm{i}=1$, $\mathrm{m} ; \mathrm{j}=1$ n

Step 2: Development of weighted normalized decision matrix can be found by multiply each normalized value (Nij) with their corresponding weight $\mathrm{Wj}$.

$$
\begin{aligned}
& \mathrm{Vij}=\mathrm{Wj} \mathrm{Nij} \\
& \text { where } \mathrm{Wj} \text { is the weight of } \mathrm{jth} \text { criterion }
\end{aligned}
$$

Step 3: Determination of solution to the multi-objective optimization problem (Calculate the composite score)

The weighted normalized scores are added in the case of beneficial or maximization objective and subtracted in the case of non-beneficial or minimization objective. Then the multi-objective optimization becomes

$$
\mathrm{Zi}=\sum_{\mathrm{j}=1}^{\mathrm{b}} \mathrm{WjX} \backslash \mathrm{ij}-\sum_{\mathrm{j}=\mathrm{b}+1}^{\mathrm{n}} \mathrm{WjX} \backslash \mathrm{ij}
$$

Where $\sum_{j=1}^{b} X{ }_{i j}, \sum_{j=b+1}^{n} X i j$ are the benefit and nonbenefit (cost) criteria, respectively.

Step 4: Rank the alternatives in descending order.

The final preference is obtained by an ordinal ranking of $\mathrm{Zi}$. Thus, the best alternative has the highest $\mathrm{Zi}$ value, while the worst alternative has the lowest $\mathrm{Zi}$ value. Table (5) was created using Equations 6,7 and 8.

Table (5) MOORA coefficient and corresponding ranking 
As illustrated in Table (5) the process setting parameter setting corresponding to highest value of MOORA coefficient represent the optimal setting of control parameters for this present study. Dependent of the totals of its maxima (beneficial attributes) and minima (cost attributes) in the decision matrix, the weighted normalized scores value $(\mathrm{Zi})$ can be positive or negative. In this study, the all values of MOORA coefficient were found negative and therefor it was treated as a multi performance characteristic index (MPCI) of each cutting combination as shown in formula (9).

$$
\text { MPCI }=1+Z i
$$

\section{(9)}

Where $\mathrm{Zi}$ is the MOORA coefficient of each cutting combination

MOORA is used to transform multiple responses into a single characteristic index known as Multi Performance Characteristic Index (MPCI).

Finally, the MPCI response can be used to find the better (near optimum) cutting combination. MPCI was optimized by using orthogonal array design. Mean values corresponding to each MPCI values have been computed and analyzed using the analysis of means (ANOM) method considering Higher-Is-Better (HB) criteria. Influence of PCA parameters on MPCI is shown in Fig (2), which indicates that MPCI tends to decrease rapidly with $\mathrm{V}$ to a minimum level and then increases. One can interpret that $\mathrm{V}$ has a significant direct impact on MPCI. Whereas, I is directly proportional to MPCI. As I increases the energy increases and therefore more heat energy is produced in the work piece that leads to increased melting and evaporation of the metal. One can interpret from Table (6) that $\mathrm{V}$ is the most important factor in affecting MPCI because it's percentage contribution is $51.40 \%$, then followed by I and SOD with the percentage contribution, $45.10 \%$ and $3.5 \%$, respectively. Figure (3) clears that there is an interaction between the process parameters in affecting MPCI. The normal probability plot of the raw data is shown in Fig (4). It shown that the raw data generally fall on a straight line indicating that the errors are distributed normally.

\begin{tabular}{|c|c|c|c|c|c|}
\hline Exp & $\Sigma \max$ & $\Sigma \min$ & $\begin{array}{l}\Sigma \max - \\
\Sigma \min \end{array}$ & $\begin{array}{l}(\Sigma \max - \\
\Sigma \min )+1\end{array}$ & $\begin{array}{l}\text { MPCI } \\
\text { Rank }\end{array}$ \\
\hline 1 & 0.029 & 0.119 & -0.09 & 0.91 & 10 \\
\hline 2 & 0.033 & 0.127 & -0.094 & $\begin{array}{ll} & 0.90 \\
6 & \end{array}$ & 14 \\
\hline 3 & 0.034 & 0.132 & -0.098 & $\begin{array}{ll} & 0.90 \\
2 & \end{array}$ & 21 \\
\hline 4 & 0.032 & 0.113 & -0.081 & $\begin{array}{ll} & 0.91 \\
9 & \end{array}$ & 6 \\
\hline 5 & 0.034 & 0.111 & -0.077 & $\begin{array}{ll} & 0.92 \\
3 & \end{array}$ & 4 \\
\hline 6 & 0.037 & 0.117 & -0.081 & $\begin{array}{ll} & 0.91 \\
9 & \end{array}$ & 5 \\
\hline 7 & 0.035 & 0.109 & -0.074 & $\begin{array}{ll} & 0.92 \\
6 & \end{array}$ & 2 \\
\hline 8 & 0.038 & 0.111 & -0.073 & $\begin{array}{ll} & 0.92 \\
7 & \end{array}$ & 1 \\
\hline 9 & 0.039 & 0.113 & -0.074 & $\begin{array}{ll} & 0.92 \\
6 & \end{array}$ & 3 \\
\hline 10 & 0.042 & 0.143 & -0.102 & $\begin{array}{ll} & 0.89 \\
8 & \end{array}$ & 23 \\
\hline 11 & 0.046 & 0.155 & -0.109 & $\begin{array}{ll} & 0.89 \\
1 & \end{array}$ & 27 \\
\hline 12 & 0.048 & 0.157 & -0.109 & $\begin{array}{ll} & 0.89 \\
1 & \end{array}$ & 26 \\
\hline 13 & 0.047 & 0.15 & -0.103 & $\begin{array}{ll} & 0.89 \\
7 & \end{array}$ & 24 \\
\hline 14 & 0.05 & 0.155 & -0.105 & $\begin{array}{ll} & 0.89 \\
5 & \end{array}$ & 25 \\
\hline 15 & 0.05 & 0.145 & -0.094 & $\begin{array}{ll} & 0.90 \\
6 & \end{array}$ & 13 \\
\hline 16 & 0.048 & 0.132 & -0.084 & $\begin{array}{ll} & 0.91 \\
6 & \end{array}$ & 7 \\
\hline 17 & 0.052 & 0.138 & -0.086 & $\begin{array}{ll} & 0.91 \\
4 & \end{array}$ & 8 \\
\hline 18 & 0.057 & 0.154 & -0.097 & $\begin{array}{ll} & 0.90 \\
3 & \end{array}$ & 18 \\
\hline 19 & 0.053 & 0.152 & -0.1 & 0.9 & 22 \\
\hline 20 & 0.057 & 0.153 & -0.097 & $\begin{array}{ll} & 0.90 \\
3 & \end{array}$ & 17 \\
\hline 21 & 0.06 & 0.157 & -0.098 & $\begin{array}{ll} & 0.90 \\
2 & \end{array}$ & 20 \\
\hline 22 & 0.06 & 0.155 & -0.095 & $\begin{array}{ll} & 0.90 \\
5 & \end{array}$ & 16 \\
\hline 23 & 0.062 & 0.152 & -0.09 & 0.91 & 11 \\
\hline 24 & 0.066 & 0.161 & -0.095 & $\begin{array}{ll} & 0.90 \\
5 & \end{array}$ & 15 \\
\hline 25 & 0.064 & 0.162 & -0.097 & $\begin{array}{ll} & 0.90 \\
3 & \end{array}$ & 19 \\
\hline 26 & 0.065 & 0.158 & -0.094 & $\begin{array}{ll} & 0.90 \\
6 & \end{array}$ & 12 \\
\hline 27 & 0.068 & 0.157 & -0.089 & $\begin{array}{ll} & 0.91 \\
1 & \end{array}$ & 9 \\
\hline
\end{tabular}


A. Hamdy, M. Fattouh, S. Abaas and R. Masoud "MULTI-OBJECTIVE OPTIMIZATION OF ..."

\begin{tabular}{|l|l|l|l|}
\hline Level & V & I & SOD \\
\hline $\mathbf{1}$ & $0.9174^{*}$ & 0.9004 & 0.9082 \\
\hline $\mathbf{2}$ & 0.9011 & 0.9087 & $0.9083^{*}$ \\
\hline $\mathbf{3}$ & 0.9051 & $0.9146^{*}$ & 0.9072 \\
\hline Delta & 0.0163 & 0.0142 & 0.001 \\
\hline Rank & 1 & 2 & 3 \\
\hline Contribution \% & $51.75 \%$ & $45.08 \%$ & $3.17 \%$ \\
\hline
\end{tabular}

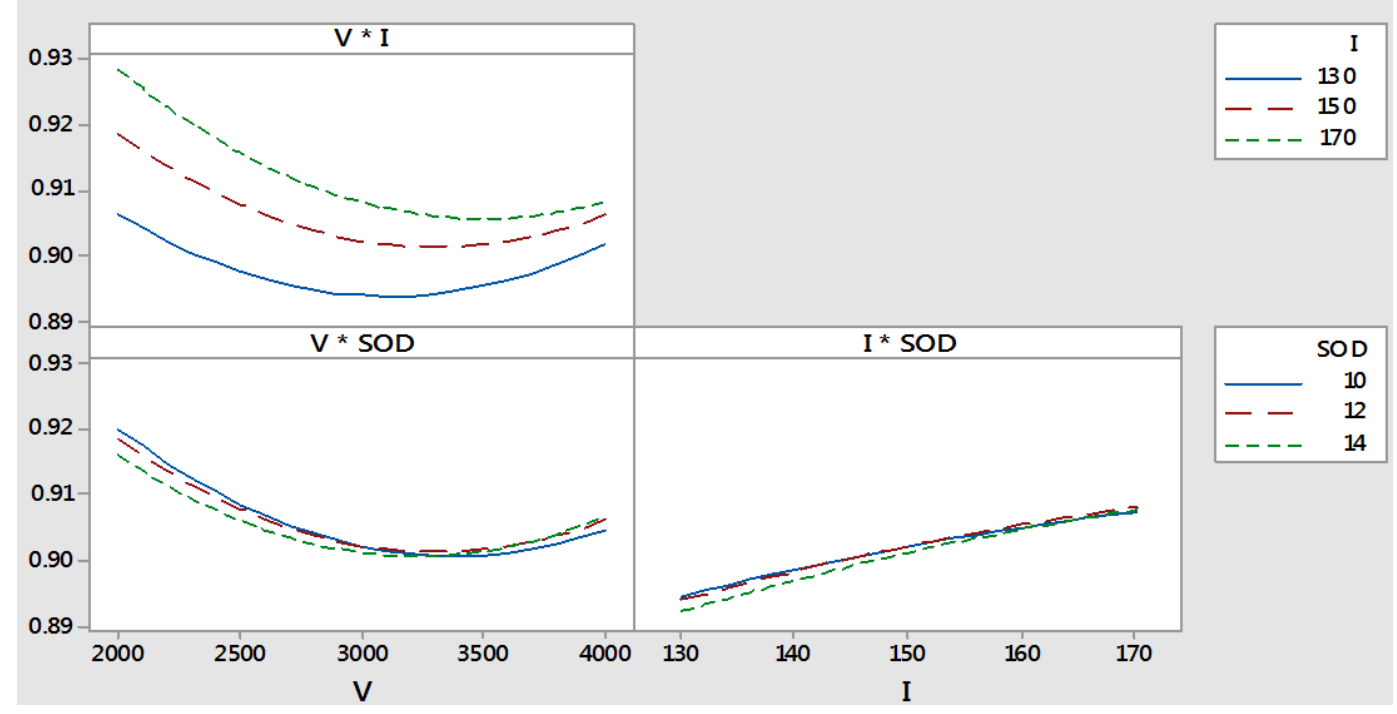

Fig (3) Interaction plot for MPCI

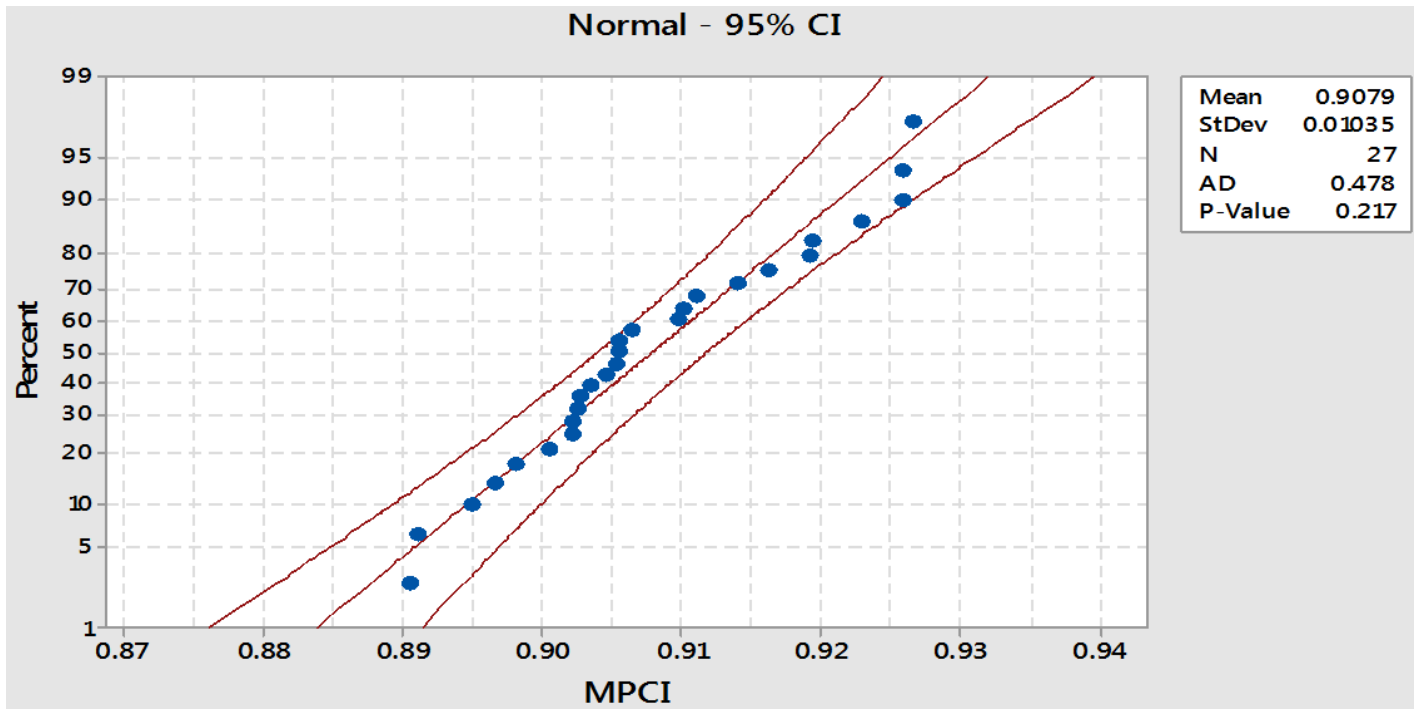

Fig (4) Normal probability for MPCI

\section{MODELING AND OPTIMIZATION OF MPCI USING}


Generally, there are three approaches to modeling cutting performance, theoretical, empirical and semiempirical approaches. Because of the unsatisfactory knowledge of the PAC process to formulate the models using a more theoretical approach at this stage of development, the models for PAC can developed using empirical models. The various methods for doing empirical models are Power equation, Exponential, logarithmic, Linear, Polynomial etc. The purpose of evolving empirical models was to relate the cutting response to the parameters and thus to facilitate the optimization of the cutting process. With these empirical models, the objective function and process constraints can be formulated, and the optimization problem can then be solved by using traditional nonlinear optimization techniques or evolutionary algorithms.

In this work MPCI of PAC process was modeled and optimized by the evolutionary approach. Power law based models are simple to understand and include the higher order modeling in itself (as the power of the variable parameters are not predefined, rather estimated from the experimental results). In this work, GA was used to assess the MPCI of PCA process based power law and optimize it [35].

\subsection{Modeling of MPCI Using Genetic Algorithm}

In that way, research conducted in this study allows precise selection of the input PAC parameters for the achieving of the best cutting conditions. In this work, genetic algorithm is implemented in the MATLAB environment. The GA code was developed in Mat lab 6.5. Model of the genetic algorithm yielded following result for MPCI

$$
\operatorname{MPCI}=C \mathbf{V}^{\alpha} \mathbf{I}^{\beta} \text { SOD }^{\gamma}
$$

where $\boldsymbol{C}, \boldsymbol{\alpha}, \boldsymbol{\beta}$ and $\boldsymbol{\gamma}$ are unknown and to be found by genetic algorithm. All of coefficients in Equation (10) are determined by minimization of $\boldsymbol{\Delta}$, which represents a sum of percent errors for every parameter, expressed through formula (11):

$$
\Delta=\sum_{i=1}^{n}\left|\frac{P(i)-D(i)}{P(i)}\right| \times 100 \%
$$

where $\mathbf{n}$ is the number of individuals that participate in every generation, $\mathbf{P}$ is the experimentally obtained value and $\mathbf{D}$ is the modeled value for every parameter. Model of the genetic algorithm yielded following result for MPCI.

$$
\text { MPCI }=0.81 \mathrm{~V}^{-0.025} \mathrm{I}^{0.064} \mathrm{SOD}^{-0.0002}
$$

The process of computing took 100 generations with 50 individuals in every generation, with heuristic crossover of parents picked from mating pool. The model of genetic algorithm predicted the MPCI with an average percent error of $13.512 \%$.

\subsection{Optimization of MPCI Using Genetic Algorithm}

The GA is a method for solving both constrained and unconstrained optimization problems and is based on natural selection, the process that drives the biological evolution. Figure (5) illustrates the flow of how the GA operates in order to optimize a problem.

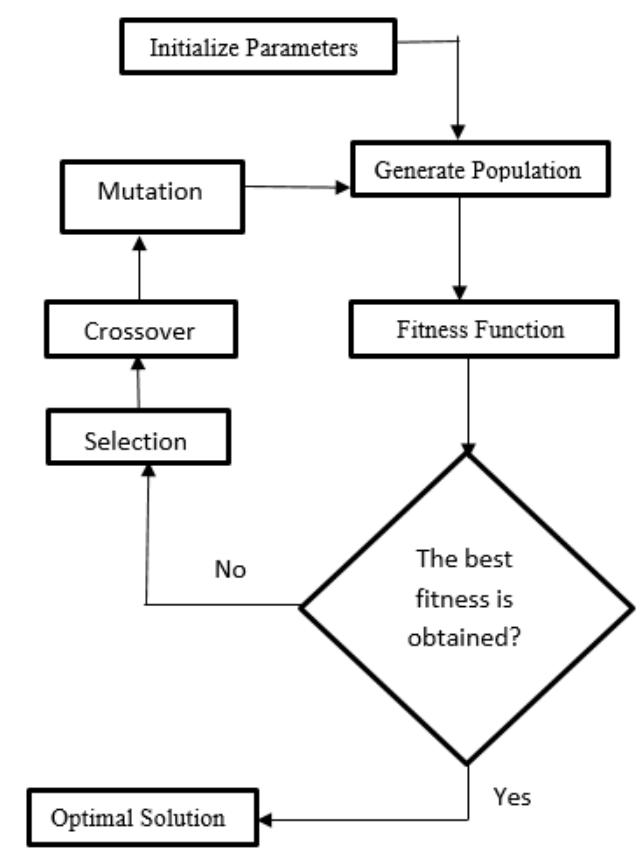

Fig (5) The flow chart of GA for optimization

The solution of an optimization problem with the GA initiates with a set of possible solution that is known as chromosomes. The entire sets of these chromosomes comprise of populations which are arbitrarily selected. The chromosomes evolve during several iterations. New generations known as offspring are generated by using the crossover and mutation techniques. Crossover involves the process of splitting two chromosomes and then joining one-half of each chromosome with the other pair. Mutation involves the process of flipping a chromosome. The GA repetitively modifies a population of individual solutions. At each step, the GA selects individuals at casual from the current population to be parents and uses them to produce the children for the next generation. Over successive generations, the population evolves toward an optimal solution [35]. The target of the optimization process in this study is to determine the optimal values of the process parameters that lead to the maximum value of MPCI. To express the optimization problem, the proposed regression model for 
MPCI is taken to be the fitness function of the optimization solution. The maximization of the fitness function value is subjected to the limitations of the process parameters. By using the fitness function, the limitations of process parameters and the GA parameters, the Mat Lab Optimization Toolbox is then applied to find the maximum values of MPCI at the optimal points.

To formulate the optimization problem, the Regression model of MPCI, Equation (12) is taken to be the fitness function of the optimization solution. The maximization of the fitness function value of MPCI is subjected to the limitations of the process parameters. The range of values of experimental process parameters is selected to present the limitations of the optimization solution. The optimization problem was expressed as follows:

Maximize MPCI (V; I; SOD)

$$
\mathrm{MPCI}=0.81 \mathrm{~V}^{-0.025} \mathrm{I}^{0.064} \mathrm{SOD}^{-0.0002}
$$

\section{Subject to}

$$
\begin{aligned}
2000<\mathrm{V} & <4000 \\
130<\mathrm{I} & <170
\end{aligned}
$$

$10<\mathrm{SOD}<14$

Basically, to obtain the optimal solutions, some criteria must be considered by the GA algorithm as recorded in Table (7).

Table (7) Combination of GA parameter rates

\begin{tabular}{|l|l|}
\hline Parameters & $\begin{array}{l}\text { Setting } \\
\text { valuelFunction type }\end{array}$ \\
\hline Population & 50 \\
\hline Scaling function & Rank \\
\hline Selection function & Roulette wheel \\
\hline Crossover function & Heuristic \\
\hline Crossover rate & 0.8 \\
\hline Mutation function & Adaptive feasible \\
\hline
\end{tabular}

The results of the Mat Lab Optimization Toolbox are given as, the set values of optimal process parameters that lead to the maximum MPCI value are $2000 \mathrm{~mm} / \mathrm{min}$ for $\mathrm{V}, 170 \mathrm{~A}$ for $\mathrm{I}$ and $10 \mathrm{~mm}$ for SOD. It is also indicated that the optimal solution is obtained at the 50 th generation. Figure (6) shows the best fitness value of the GA is 0.925792 with the mean fitness value being 0.925794 .

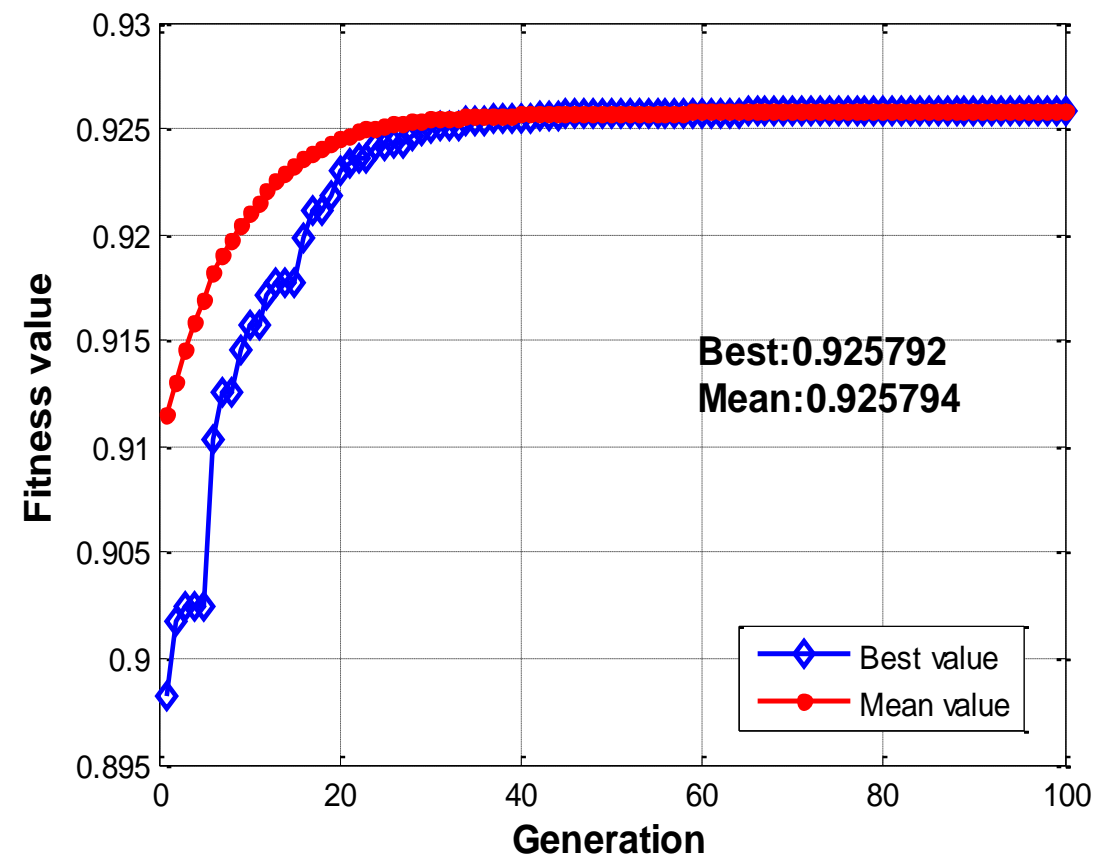

Fig (6) Fitness function plot of GA

Figure (7) shows 3D surface plot of MPCI according to various values of arc current and cutting speed at concentration level of standoff distance ( $\mathrm{SOD}=12 \mathrm{~mm}$ ). High values arc current and high values of cutting speed favor high value of MPCI. From Fig (8), at concentration value of arc current ( $\mathrm{I}=150 \mathrm{~A})$ It can be interpreted that overall MPCI value is less in the region of low cutting speed then it increases at high values of cutting speed while all

values of standoff distance favor high values of MPCI. From Fig (9), at concentration value of cutting speed $(\mathrm{V}=3000 \mathrm{~mm} / \mathrm{min})$ higher values of arc current and 


\section{A. Hamdy, M. Fattouh, S. Abaas and R. Masoud "MULTI-OBJECTIVE OPTIMIZATION OF ..."}

higher values of standoff distance favor higher values of MPCI.

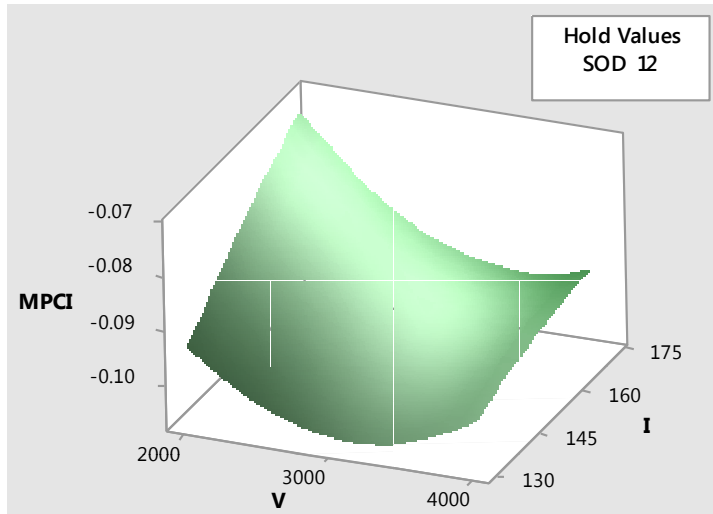

Fig (7) Surface plot of MPCI versus I and V

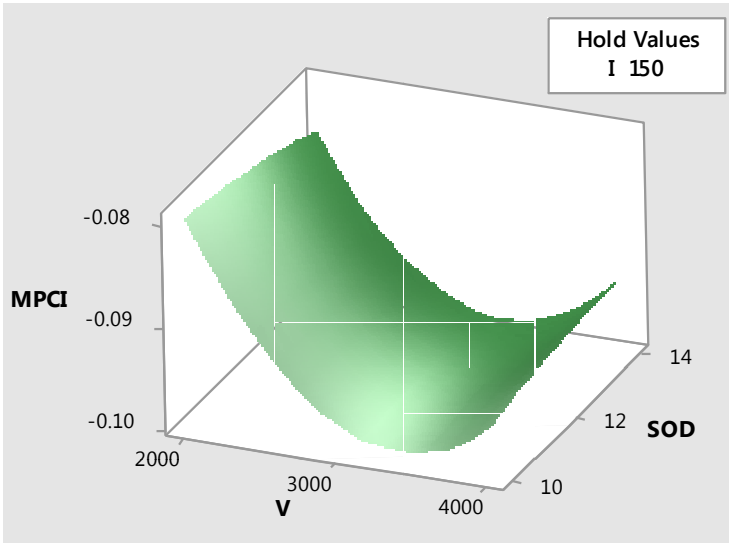

Fig (8) Surface plot of MPCI versus SOD and V

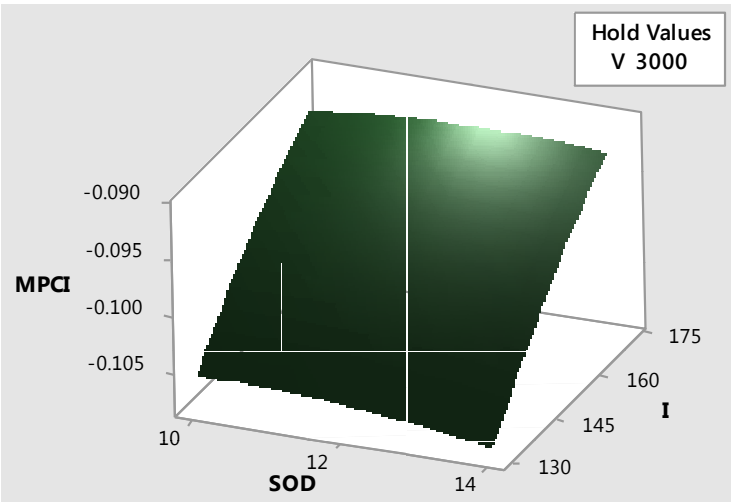

Fig (9) Surface plot of MPCI versus I and SOD

\section{CONCLUSION}

This study contributes to the existing problems related to the multi-objective optimization of PAC process. A large number of experiments ( 27 experiments) were conducted at different levels of cutting speed, arc current and standoff distance for optimization the cutting characteristics of straight-slit cutting (kerf taper, dross, surface roughness and material removal rate). It is, therefore, concluded that

1-The ANOM, (SDV-MOORA-GA) method has successfully optimized the plasma arc cutting process parameters used in this study.

2 - The arrangement of process parameters no. 7 has the maximum MPCI among the 27 experiments and the best possible optimum conditions of this process are the following: $2000 \mathrm{~mm} / \mathrm{min}$ of cutting speed, $170 \mathrm{~A}$ of current and $10 \mathrm{~mm}$ of standoff distance.

3 - The cutting speed is the most factor in affecting MPCI because it's percentage contribution of $51.40 \%$, then followed by I and SOD with the percentage contribution of $45.10 \%$ and $3.5 \%$, respectively.

4- High values arc current and high values of cutting speed at constant level of standoff distance favor high value of MPCI.

5- At constant value of arc current it can be interpreted that MPCI value is less in the region of low cutting speed then it increases at high values of cutting speed while all values of standoff distance favor high values of MPCI.

6- At constant value of cutting speed with higher values of arc current and higher values of standoff distance favor higher values of MPCI.

\section{ACKNOWLEDGMENTS}

The authors greatly acknowledge Techno Steel Company at Industrial Sadat City. Egypt, for providing the opportunity to accomplish the experimental work on CNC Air Plasma Arc Cutting Machine (model SF2012GC).

\section{REFERENCES}

1. Feldshtein E, Pata las-Maliszewska J, Kłos S, Ka łasznikow A, and Andrzeje wski K, "The Use of Plackett-Burman Plans and The Analysis of Expert Opinions, In Order to Assess the Significance of Controllable Parameters of the Plasma Cutting Process". Eksploatacja I Niezawodnosc - Maintenance and Reliability, Vol. 20, PP. 443-449,2018.

2. Kechagias, J., Petousis, M., Vidakis, N., and Mastorakis, N. "Plasma Arc Cutting Dimensional Accuracy Optimization Employing the Parameter Design Approach". ITM Web Conf, Vol. 9, PP. 1-4. 2017.

3. Balaganesh, S., Dinesh, T., Kumar, B.D., Hariharan, S., and Kumar, N.S. "Experimental Investigation on Process Parameters of E250 Mild Steel in Plasma Arc Cutting". Int J Mod Trends Sci Technol, Vol.11, PP. 81-88, 2017.

4. Sahil Sharma, Mukesh Gupta, Raj Kumar, and N. S Bindra, "Experimental Analysis and 
Optimization of Process Parameters in Plasma Arc Cutting Machine of EN-45A Material Using Taguchi and ANOVA Method", International Journal of Mechanical and Industrial Engineering, Vol .11, PP.1394:1398,2017.

5. Mastorakis, "Optimization of Cut Surface Quality during CNC Plasma Arc Cutting process", Int. J. of Systems Applications, Engineering \& Development, Vol. 10, PP-305308, 2016.

6. M. Santhana kumar, and R. Adalarasan, "Parameter Design in Plasma Arc Cutting of Galvanised Iron Sheet Using Desirability Function-Based Response Surface Methodology" International Journal Manufacturing Research, Vol. 10, PP. 199-214, April 2015.

7. K. P. Maity, and D. K. Bagal, "Effect of Process Parameters on Cut Quality of Stainless Steel of Plasma Arc Cutting Using Hybrid Approach", Int. Journal of Adv. Manufacturing Technology, Vol. 2, PP. 712-723, 2014.

8. Kechagias, P. Stavropoulos, S. Maropoulos, and K. Salonitis, "On the multi - parameter optimization of CNC plasma-arc cutting process quality indicators using Taguchi Design of Experiments", Recent Advances in Electrical Engineering, Vol.6, PP.128-133, 2014.

9. Milan Kumar Das, Kaushik Kumar, Tapan Kr. Barman and PrasantaSahoo, "Optimization of Process Parameters in Plasma Arc Cutting of EN31 Steel Based on MRR and Surface Roughness Using Grey Relational Analysis", International Conference on Advances in Manufacturing and Materials Engineering, Procedia Technology, Vol. 5, PP. 1550 - 1559, 2014.

10. Kulvinder Rana, Parabhakar Kaushik, and Susmit Chaudhary, "Optimization of Plasma Arc Cutting by Applying Taguchi Method", International journal of enhanced Research in science Technology \& Engineering, Vol. 2, PP.106-110, 2013.

11. Subbarao Chamarthi, N. Sinivasa Reddy, Manoj Kumar Elipey, and D.V. Ramana Reddy, "Investigation Analysis of Plasma Arc Cutting Parameters On the Unevenness Surface of Hardox-400 Material", International Conference on Design and Manufacturing, Vol. 64, PP.854-861,2013.

12. Bogdan Nedić, Marko Janković, Miroslav Radovanović, and Gordana Globočki Lakić, "Quality of Plasma Cutting", SERBIATRIB '13,13th International Conference on Tribology Kragujevac, Serbia, Vol.6, PP.314:319, 15 - 17 May 2013.
13. Bhuvenesh $\mathrm{R}$, Norizaman $\mathrm{MH}$, and Manan MSA, "Surface Roughness and MRR Effect on Manual Plasma Arc Cutting Machining", World Acad Sci Eng Technol, Vol. 62, PP.503506,2012.

14. Özek C, Çaydaş U, and Ünal E, “A fuzzy Model for Predicting Surface Roughness in Plasma Arc Cutting of AISI 4140 Steel'. Mater Manuf Process, Vol.102, PP.27:95,2012.

15. HatalaM, Ungureanu N, Michalik $P$, and et al, "Influence of Factors of Plasma Cutting on Surface Roughness and Heat Affected Zone", $2^{\text {nd }} \quad$ International Conference Manufacturing Engineering\& Management, Vol.4, PP. 70-73,2012.

16. K. Salonitis, and S. Vatousianos, "Experimental Investigation of the Plasma Arc Cutting Process", Procedia CIRP, Vol. 3, PP. 287 -292, 2012.

17. Concetti A, "Integrated Approaches for Designing and Optimizing Thermal Plasma Processing for Metal Cutting and Material Treatment", PP. 1-197,2011.

18. Miroslav Rodovanovic, and Milos Madik, "Modeling the Plasma Arc Cutting Process Using ANN", Nonconventional Technologies Review, Vol. 4, PP. 43-48, 2011.

19. Kechagias J, and Billis M, "A parameter Design of CNC Plasma Arc Cutting of Carbon Steel Plates Using Robust Design", Stergios Maropoulos, Vol.12, PP.315-326,2010.

20. S.M. Ilii, M. Coteata, and A. Munteanu, "Experimental Results Concerning the Variation of Surface Roughness Parameter (Ra) At Plasma Arc Cutting of A Stainless Steel Work Piece", International Journal of Modern Manufacturing Technologies, Vol.6, PP. 31-36, 2010.

21. J.C. Chen, Y. Li, and R.I. Cox, "TaguchiBased Six Sigma Approach to Optimize Plasma Cutting Process: An Industrial Case Study", International Journal of Advanced Manufacturing Technology, Vol.41, PP.760769, 2009.

22. Hatala IM, and Orlovský, "Mathematical Modeling of Plasma Arc Cutting Technological Process", 13th International Research/Expert Conference, Trends in the Development of Machinery and Associated Technology, PP. 6568, 2009.

23. Asiabanpour B, Vejandla DT, Novoa C, and et al, "Optimizing the Quality of Parts Manufactured by the Automated Plasma Cutting Process Using Response”, Manuscripts in the Twentieth Annual International Solid Freeform Fabrication (SFF) Symposium, Vol.14, PP. 47- 60 ,2009. 
24. Ferreira P, Melo I, Gonçalves-coelho A, and Mourão "A Plasma Cutting Optimization by Using the Response Surface Methodology", The Annals of "Dunărea De Jos" University of Galaţi, Vol .6, PP.213-218,2009.

25. R. Bini, B.M. Colosimo, A.E. Kutlu, and M. Monno, "Experimental Study of the Features of the Kerf Generated by a 200A High Tolerance Plasma Arc Cutting System", Journal of Materials Processing Technology, Vol.196, PP.345-355, 2008.

26. Ismail.Kakaravada, A. Mahamani and V., "Pandurangadu Optimization of Machining Parameters Using Entropy- VIKOR Method in Drilling of A356-TiB2/TiC in-Situ Composites", The 3rd International Conference on Materials and Manufacturing Engineering IOP Publishing IOP Conf. Series: Materials Science and Engineering, Vol .6, PP.1-6, 2018.

27. N.D. Chakladar and S. Chakraborty, "A combined TOPSIS-AHP-Method-Based Approach for Non-traditional Machining Processes Selection", Journal of Engineering Manufacture, Vol.222, pp.1613-1623,2008.

28. A. Singh, S. Datta and S.S. Mahapatra, "Application of TOPSIS in Taguchi Method for Optimal Machining Parameter Selection", Journal of Manufacturing Science and Production, Vol. 11, PP. 49-60,2011.

29. Gadakh, V.S., Shinde, V.B. and Khemnar, N.S., "Optimization of Welding Process Parameters Using MOORA Method", The International Journal of Advanced Manufacturing Technology, Vol. 69, PP. 2031-2039, 2013.

30. Chaturvedi, V., Jain, A., Bhadauriya, A. and Tomar, K., "Parametric Optimization of ECM Process Parameters by MOORA Method", International Journal of Research in Engineering and Applied Sciences, Vol. 4, PP. 1-10, 2014.

31. Gadakh, and V.S., "Application of MOORA Method for Parametric Optimization of Milling Process", International Journal of Applied Engineering Research, Dindigul, Vol. 1, PP. 743-758, 2011.

32. Rajesh, S., Rajakarunakaran, S., Suthakarapandian, R. and Pitchipoo, P., "MOORA-Based Tribological Studies on Red Mud Reinforced Aluminum Metal Matrix Composites", Advances in Tribology, Vol.8, PP. 1-8,2013.

33. Ray, A., "Green Cutting Fluid Selection Using Multi-Attribute Decision Making Approach", Journal of the Institution of Engineers (India): Series C, Vol. 96, PP. 35-39, 2014.

34. El-Santawy, M.F. and Ahmed, A.N, "Analysis of Project Selection by Using SDV-MOORA
Approach”, Life Science Journal, Vol. 9, PP. 129-131,2012.

35. Marin Gostimirovic1, Vladimir Pucovsky, Milenko Sekulic, Miroslav Radovanovic and Milos Madic, "Evolutionary Multi-Objective Optimization of Energy Efficiency in Electrical Discharge Machining", Journal of Mechanical Science and Technology, Vol.10, PP.47754785, 2018 